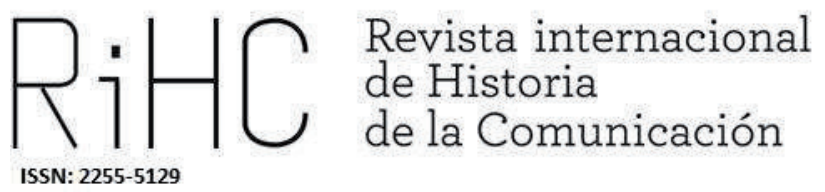

\title{
PARA UNA GENEALOGÍA DEL OFICIO DE "FIGURINISTA" EN PORTUGAL. UNA LUCHA DE GÉNERO EN CURSO
}

For a genealogy of the craft of "costume designer" in Portugal. An ongoing gender discussion

DOI: http://dx.doi.org/10.12795/RiCH.2021.i16.08

Recibido: 22-4-2021

Aceptado: 3-6-2021

Publicado: 30-5-2021

\section{Caterina Cucinotta}

Universidade NOVA de Lisboa, Portugal

caterinacucinotta@fcsh.unl.pt

ORCID (i) https://orcid.org/0000-0002-0572-6930 
Resumen: Analizar el cine y citar solamente el trabajo de dirección resulta ser la metodología elegida en más ocasiones por los investigadores y científicos de film studies. Este método de análisis, de hecho, está tan aceptado en la academia que hasta se despliega con absoluta normalidad por la mayoría de los artistas hombres que trabajan o han trabajado en el cine (Chaplin, Rossellini, Fellini, Hitchcock, Godard, Truffaut, De Oliveira, entre algunos ejemplos). La "Big history" del cine, tal como se aprende, se construyó a partir de la mirada de los grandes directores. Estos han construido un discurso en el que se hacen responsables absolutos de la creación, la materialización y la ordenación de las imágenes en movimiento que constituyeron las grandes obras del séptimo arte que conocemos y analizamos. Sin embargo, existe toda una serie de artesanías y artes que, a pesar de sufrir un absoluto olvido, cuentan con una abrumadora mayoría de trabajadoras y artistas. Por ejemplo, en los principios del cine, el trabajo de las montadoras quedó relegado a la simple técnica de corta y pega y, en 2020 (Schultz en Cordero-Hoyo et al.) ya estábamos seguros de que el departamento cinematográfico que en España y Portugal tiene el mayor número de mujeres, es el de diseño de vestuario (figurinos o guarda-ropa). En particular, en Portugal este arte se reduce a una mera función técnica con consecuencias salariales y de descrédito también reflejado en su terminología técnica. A través de algunos study-cases abarcados durante el proyecto posdoctoral (en curso), financiado por FCT, centraremos nuestra atención en cuestiones de género que en sus historias, las diseñadoras de vestuario, las jefas de guarda-ropa y las costureras del cine portugués, abordaran en entrevistas realizadas en 2017 y analizadas a través de la metodología de la historia oral.

Palabras clave: Teoría del cine; estudios de género; diseño de vestuario; cine portugués, historia from below.

Abstract: Talking about cinema and citing only the work of direction, it turns out to be the methodology more chosen by the majority of researchers of Film studies. This method of analysis, of course, is so accepted in the academy that we accept with absolute normality that the majority of the artists who work and have worked in cinema have been and are men (Chaplin, Rossellini, Fellini, Hitchcock, De Oliveira among others). The cinema "Big History", as we studied it, is based on the great directors who created, materialized and ordered the images in motion that became the great works of the seventh art that we know and analyse. However, there is a whole range of professions, arts and crafts that, in spite of enduring absolute contempt, deal with an overwhelming majority of workers and artists women. For example, in the beginning of cinema, the editing work was relegated to the simple technique of cutting and picking and, in 2020 (Schultz en Cordero-Hoyo et al.) we are sure that the cinema department in Spain and Portugal there are the largest number of women, today, is the costume design (or wardrobe). In particular, in Portugal this art is reduced to a mere technical function with wage consequences and discredit also in terms of its terminology. The negative way that fashion continues to be considered as this universe where only women can dedicate themselves, results in devaluation, absence of emancipating practices and of active participation that has its beginning in the "univocal" way as it has always considered itself the cinema through its "Big History". Through some study-cases that were covered during the postdoctoral project (in course) financed by FCT, we will focus our attention on gender and feminist surveys that in their stories, costume designers, wardrobe assistants and tailors in Portuguese cinema, covered in interviews conducted in 2017. These stories can change and must change the way we see, study and analyse the great history of cinema. 
Keywords: Film theory; gender studies; costume design; Portuguese cinema; history from below.

\section{Introducción de una teoría: ¿̇la figurinista es cineasta?}

El debate en torno a la relación entre los estudios fílmicos y los estudios de género no es nuevo: las cuestiones han girado y giran en torno a la presencia desigual de la mujer en el cine (Lauretis, 1985; Dall'Asta, 2008; Pereira, 2016). Estos estudios nunca mencionan cómo los departamentos de vestuario siempre se han registrado entre los mayores números de trabajadoras de este arte (Scholz y Álvarez, 2018).

Este artículo aborda el estudio de las trabajadoras del cine en Portugal, entre el comienzo de la dictadura salarazista y el final de los años '90 del siglo XX, basando la investigación en una intersección entre la historia oral y las fuentes de la historia del cine.

Pero el debate siempre ha tenido en su punto de partida una perspectiva única en la que el cine siempre ha sido considerado a través de su "Big history" (Rondolino, 2000) y no como un ensamblaje de historias "from below" (Thompson 1991; Burke, 2001), resultando en una devaluación o ausencia de las prácticas emancipadoras y de participación activa de los demás departamentos (Cook, 1996).

Para desarrollar teóricamente esta falta, tomaremos como un punto de referencia a Jacques Aumont quien en 2004 abrió el debate de las teorías cinematográficas a otras profesiones artísticas que crean el cine. En la introducción a Teorías de los cineastas, Aumont (2004) comienza cuestionando la veracidad de una teoría del cine que toma en cuenta el trabajo del director como único "inventor de formas" (2004: 13). Aumont admite que escribir sobre cine y mencionar sólo al director debe ser visto como una "concepción no absoluta".

Esta metodología de análisis, de hecho, está muy aceptada en el ámbito académico. No se debería aceptar como naturalizado en un cierto sector de la cultura y de la comunicación, como es la producción cinematográfica, en que la mayoría de los artistas que trabajan y han trabajado en cinematografía han sido y son hombres.

En este sentido, Aumont admite que hay un desvío, incluso menciona caminos alternativos, pero termina por no correr el riesgo de recorrer alguno de estas nuevas líneas de investigación. Al mencionar el camino teórico e intelectual que otros estudiosos han recorrido antes, Aumont acepta cierta espontaneidad en la concepción 
de la historia del cine como "un relato heroico de los grandes hombres y sus impulsos, aventuras y obstáculos" (p. 13).

Por ello, pensamos que su definición de cineasta se acerca más al cuestionamiento y no se reduce a una interpretación cerrada. Al buscar pistas para una nueva apertura en lo que él define como "cineasta", Aumont se pregunta:

¿Pero quién es cineasta? En lo referente a la teoría de los cineastas, la cuestión parece secundaria (o ya zanjada): son los realizadores quienes han hecho la historia del cine. Sin embargo, lo importante es darse cuenta de que dicha concepción no es absoluta. Pensada de manera espontánea, la historia del cine se asemeja mucho a un relato heroico de grandes hombres y sus impulsos, aventuras y obstáculos; así la explican, cada uno a su modo, los dos libros de Gilles Deleuze y las Histoire(s) do cinema, de Jean Luc Godard: historia romántica y mítica, engañosa como el mito y dotada, como este, del peso de su propia pseudoevidencia. Así, en este libro, como en todas partes, nos interesaremos únicamente por los realizadores. (2004: 13).

Una mirada inclusiva, de género y más abierta a otras figuras profesionales, engloba al "inventor de formas" como punto de partida para que estas mismas formas se materialicen. Si el director inventa las formas del cine, el director de arte y el director de fotografía, entre otros, intentan materializarlas. Con las palabras de Jacques Aumont:

Sin olvidar que habría sido posible una opción más amplia, y que podría haberme interrogado por las aportaciones teóricas de directores de fotografía, guionistas, productores e incluso montadores, subscribo, sin excesivo remordimiento, la idea de la encarnación del arte en su realización. (2004: 14).

Para este propósito pensamos que la interpretación de Manuela Penafria de la "teoría de los cineastas" es adecuada para la creación de una mirada teórica diferente al arte cinematográfico a través de otros oficios.

Sin negar la diversidad de pensamientos individuales y coherentes que configuran la eventual "teoría" de cada cineasta, lo que más nos interesa es la forma de construir ese pensamiento $y$, en este sentido, lo singular muestra que hay una similitud en la elaboración de ese pensamiento. ${ }^{1}$ (2016: 9).

Por tanto, hablamos de "construcción del pensamiento del cineasta" y no podemos excluir otras figuras que contribuyan a esta construcción. A partir de entonces, "libros, manifiestos, cartas, entrevistas y otros, pero siempre de los propios cineastas" (Penafria,

\footnotetext{
${ }^{1}$ Não negando a diversidade de pensamentos individuais e coerentes que enformam a eventual "teoria" de cada cineasta, o que mais nos interessa é o modo de construção desse pensamento e, nesse sentido, o singular evidencia haver semelhança na elaboração desse pensamento.
} 
2016: 10) para uso propio del investigador son el punto de partida que, sin duda, hace la conexión entre una mirada más inclusiva de la profesión del figurinista.

La "Teoría de los cineastas" es (...) un enfoque y no una metodología. Pero, en efecto, el principal objetivo es seguir un determinado camino metodológico en el ámbito de los estudios científicos sobre cine o, más ampliamente, en los estudios sobre imagen y sonido. Como enfoque, es una línea de investigación en la que "cineasta" es un término que se extiende a todos y cada uno de los creativos más allá del director (ejemplos son actores y actrices, editores, directores de fotografía, etc.). ${ }^{2}$ (Penafria, 2016: 10)

\section{La situación en el cine en Portugal}

Coincidimos con Jacques Aumont y, en la interpretación que de él hace Manuela Penafria a través de la "Teoría de los cineastas": el figurinista es cineasta tanto como todos los demás coautores de la película. Por esto, en abril de 2017, se entrevistaron ${ }^{3}$ a varios profesionales del departamento de vestuario del cine portugués. Pudimos entrevistar a trece profesionales, desde figurinistas hasta asistentes. El propósito era llenar un vacío informativo, académico y artístico sobre el diseño de vestuario en Portugal. Con gran sorpresa, nos dimos cuenta de que todas las entrevistadas fueron mujeres.

Las entrevistas fueron dirigidas a figurinistas y asistentes de vestuario que trabajaban o que habían trabajado en el cine. Como veremos, el término más técnico "guarda-roupa" comenzó a usarse a mediados de la década de 1980, cuando la prevalencia de trabajadoras en este sector era de mujeres. A partir de esta reflexión, en el presente artículo la historia del cine se empujará "from below" para problematizar aún más el papel del género en los diferentes departamentos, con una atención específica al vestuario y al cine portugués.

\footnotetext{
${ }^{2}$ A "Teoria dos cineastas" é (...) uma abordagem e não uma metodologia. Mas, com efeito, o principal objetivo é percorrer um determinado caminho metodológico no âmbito dos estudos científicos sobre cinema ou, de modo mais alargado, nos estudos sobre a imagem e sobre o som. Enquanto abordagem trata-se de uma linha de investigação em que "cineasta" é um termo que se alarga a todo e qualquer criativo para além do realizador (são disso exemplo, os atores e atrizes, montadores/as, diretores de fotografia, etc.).

${ }^{3}$ Las entrevistas resultan de una colaboración con Nivea Faria de Souza, profesora de dirección artística en varias universidades brasileñas. El proyecto de las entrevistas ha sido pionero y sirvió como base para la genealogía de una historia de la profesión en Portugal. Para un profundizado de la metodología de la historia oral, se aconseja la lectura de Cucinotta, en Cunha, Penafria y Fernandes (2019: 57-70).
} 
De la intersección entre teoría e historia, surgen tres etapas diferentes que corresponden a tres períodos distintos de la historia del cine y, en general, de la historia social y cultural de Portugal:

1. Desde los años ‘ 30 hasta los ‘ 50 , los hombres se impusieron en la misión principal como figurinistas en Portugal. En particular, algunas personalidades femeninas sobresalen en dos o tres películas. Vamos analizar algunos ejemplos concretos a lo largo del texto.

2. En los años ' 60 y '70, paradójicamente, con los primeros cambios culturales, (concretamente Nuevo Cine) atribuyendo una menor importancia económica al vestuario, hay una mayor inclusión de la mujer en la profesión.

3. Además, a finales de los '80 la profesión se devalúa a una técnica simple en la denominación de "guarda-roupa" en lugar del artístico figurinista. Así que nos hacemos la siguiente pregunta: ¿Los presupuestos reducidos permiten que las mujeres emerjan como diseñadoras de vestuario?

Ponemos como problematización central la razón por la cual las mujeres fueron "relegadas" a unas y otras profesiones y, sin embargo, enfatizamos cómo el trabajo artístico realizado se devaluó a la mera función técnica por una cuestión de género. De hecho, el eje "cine, moda y materialidad" descansa en el concepto de technè, tal como nos lo transmitieron los antiguos griegos en un cruce equilibrado entre arte y técnica, donde la técnica por sí sola es también arte.

El cine es exactamente como el arte por excelencia, construido sobre la técnica de varios trabajadores que, todos juntos, son capaces de canalizar sus procesos creativos individuales hacia el resultado final que será la película. Pensando muy a menudo en el binomio "cine-moda", nos centramos en lo representado en la película, en los significados materiales frente a la narrativa (actores y actrices y sus revestimientos), como si todo lo que se enmarca en el encuadre sucediera allí por casualidad o por derecho allí siempre hubiera existido igual que se nos ha mostrado. En realidad, las relaciones más singulares se presentan ante nosotros solo cuando dejamos de lado la narrativa principal de la película y nos detenemos en contenidos alternativos.

Una de estas alternativas viene dada por un hecho histórico: tras la preponderante presencia de mujeres en las salas de montaje y de color del cine mudo (Pierotti, 2011), parece que las mujeres han vuelto a los talleres de moda de donde venían. En los inicios del cine, el trabajo de montadora quedaba relegado a la simple técnica de cortar y pegar, por eso las mujeres con experiencia en corte y costura en los atelieres de moda eran muy solicitadas como montadoras (Bruno, 2014). Hoy el departamento cinematográfico que en España y Portugal tiene el mayor número de mujeres es el de vestuario (Scholz, 2020) 
De acuerdo con Scholz (2020: 33), por ejemplo, en España, la media de 54,07\% de mujeres que trabaja en producciones cinematográficas, lo hace en el departamento de Costume design, superado solo por el departamento de Make-up and hairdressing (media de 62,46\%). Se trata de los porcentajes más altos entre las profesiones artísticas del cine ${ }^{4}$. En Portugal, a partir de las páginas de internet profesionales, los datos que aparecen resultan muy parecidos con una preponderancia de mujeres en los mismos departamentos ${ }^{5}$.

Durante mucho tiempo, la profesión de figurinista fue relegada a un plano más técnico y menos artístico, tomando en consideración la obligación de tener que vestir a los actores y a las actrices, descuidando toda la materialidad y estética fílmica que ello conllevaba.

No es casualidad el término, utilizado en Portugal, que define la profesión de figurinista en los títulos de las películas: al llamarlo "guarda-roupa" se da directamente al objeto y al espacio que son utilizados por él, pero no describe su verdadera presencia y prácticas $^{6}$.

El figurinista se convierte en un "guarda-roupa", mientras que el escenógrafo, a lo largo de los años, se ha transformado de "decorador" a "director de arte". Un salto hacia adelante para la profesión de escenógrafo, muy a menudo realizado por hombres. Un salto hacia atrás para la profesión de figurinista, muy a menudo poblada por mujeres.

De acuerdo con las entrevistas, se ha obtenido la pista que explica que, en Portugal, la profesión, a partir del Nuevo Cine, ha tenido una mayoría de mujeres. Además, en varios casos documentados, estas mismas mujeres también han trabajado en los dos departamentos (figurinistas y escenografía) sin por eso tener un aumento en el sueldo 7 .

Por otro lado, Portugal refleja un tipo de cinematografía periférica, menos industrializada y más dedicada a un tipo de nicho, la producción de autor, con referencias, no sólo en el campo teórico sino también en el narrativo, al cine francés de la Nouvelle Vague. El cine portugués, en su sentido de "cine de autor", ha dejado de ocuparse de los nombres de "otras" profesiones que no son el director, el director de fotografía y poco más.

\footnotetext{
${ }^{4}$ El artículo de Scholz se refiere a datos desde 2007 hasta 2015. En Portugal no existe un estudio tan detallado. Por eso, en el presente artículo la autora se refiere a las entrevistas como punto de partida para un desarrollo de datos futuros.

${ }^{5}$ En la web https://www.cineguiaportugal.pt/index.php al enlace "guarda-roupa" se nota claramente una mayoría de mujeres. Algunas denominaciones están solo al femenino ("costureira" y "mestre costureira").

${ }^{6}$ Para profundizar en la parte terminológica se aconseja la lectura de Cucinotta (2020: 146-162).

${ }^{7}$ La figura de Jasmim de Matos en el punto 2 será una clave fundamental para la comprensión de esta génesis.
} 
Como sucedió en otros campos de la cultura y de los medios de comunicación que tenían la moda, la costura, el bordado como tema central, los periódicos y las revistas, por ejemplo, comenzaron a ser dirigidos por mujeres.

Para Lipovetsky (2000), desde las primeras décadas del siglo XX hasta la actualidad, la prensa femenina exalta el uso y consumo de productos cosméticos junto al de prendas de moda, de forma que la belleza pasa a ser descrita como una conquista personal del criterio de cada mujer. Resulta lógico entender cómo la existencia de un concepto considerado como prensa femenina demuestra que todo el ámbito femenino existe como una supuesta oposición a lo masculino, mientras que la asignación de funciones masculinas son consideradas como elementos universales y referenciales del poder, el estatus y la realización profesional. (Luque Ortiz y Pérez Curiel, 2018: 122).

Una reflexión de este tipo admite que en revistas especializadas en moda y cosmética, las directoras editoriales fueron mujeres: un nicho creado a propósito para que la diferencia entre lo masculino y lo femenino sea visible. Este nicho recuerda cómo el cine hecho por mujeres, por ejemplo, suele referirse a temas concretos. Es decir, reproduce los viejos estereotipos de la división por género.

De las entrevistas, de hecho, quedó claro que la condición de mujer en una meseta era una ventaja en el momento en que la producción ejecutiva de una película podía contar con tareas de economía doméstica (Cucinotta, 2020). Así, hoy en día, es urgente definir cuál fue ese camino histórico que relegaba a los diseñadores de vestuario a simples "guarda-roupa".

A la media indicada anteriormente relacionada con el departamento de Costume design, juntamos aquí la desastrosa media que acompaña la profesión con menos mujeres: se trata de la dirección de fotografía que, con una media de 5,81\%, en el gráfico que se refiere a España, propuesto por Scholz es el porcentaje más bajo. En Portugal la situación empeoraría: hasta 2020, en la web de la AIP (Associação Imagem portuguesa) las mujeres que ocupan el puesto de Directora de fotografía son solo cuatro ${ }^{8}$.

Sin embargo, de acuerdo con la introducción de este artículo, comenzaremos por considerar un análisis más profundo que divide la historia del cine portugués en tres partes.

\footnotetext{
${ }^{8}$ Los miembros son cerca de 50. Datos disponibles en: http://www.aipcinema.com/. Acceso: 19 de mayo de 2021
} 


\section{De los '30 a los '50: ¿Dónde están las mujeres?}

La primera parte comienza con el primer cine sonoro, de los años treinta a los cincuenta. Es un cine del régimen, muy dedicado a la justificación de conceptos y metodologías propagandísticas como el colonialismo, el sometimiento cultural y social de la mujer, el encubrimiento de las libertades individuales en favor de la comunidad, el uso metódico y sistemático de la censura por parte del estado y la autocensura artística de los cineastas.

Por tanto, tomando como análisis este trozo de la historia del cine portugués, la profesión del figurinista, como se nos cuenta en su nacimiento a través del teatro, está poblada de figuras que pasan de un ámbito a otro, según las actividades de producción.

José Barbosa (1900 - 1977), Pinto de Campos (1908 - 1975), Alberto Anahory (1906 2000) y Alvaro Costa Paiva son los figurinistas que pasan del teatro al cine, también gracias a la creación de ateliers de corte y costura que realizaban, vendían y alquilaban las piezas por encargo para el cine y para el teatro.

Muy a menudo, en los títulos de las películas aparecen asociados a las más variadas denominaciones de la profesión: indumentaria, vestuario, figurinos, etc., pudiendo, en algunos casos, estar acompañados de asistentes y ayudantes. De hecho, según la información recopilada a través de las entrevistas de 2017, sabemos que su presencia en el plató fue esporádica, si no absolutamente inexistente.

Anahory, el más longevo de esta primera generación de figurinistas, es sobre el que podemos recopilar más información. Es recordado por quienes tuvieron el privilegio de trabajar a su lado como un gran diseñador, un sastre muy hábil a quien se le propusieron guiones que, según la cantidad de trabajo, aceptaba de buen grado. El proceso creativo comenzaba con el director y el productor, para luego continuar el resto del trabajo cerrado en su atelier con sus asistentes.

Su práctica consistía, recogido a través de la historia oral, en que nunca iba al set ni enviaba a sus sastres asistentes: en el plató quienes se encargaban del vestuario eran personas designadas por la producción, que muy a menudo también ocupaban otros roles (además de dedicarse a producción, también había asistentes de dirección, asistentes de edición y entourage del actor o actriz). Quien se ocupaba del vestuario era casi siempre una figura femenina ya presente en el plató para otras tareas y sobre todo ya acostumbrada, por educación cultural, a tener que ocuparse de lavar, remendar, ordenar y vestir / desvestir.

De acuerdo con Baptista y Alves, las mujeres venían de una ideología que las había dejado, durante mucho tiempo, fuera de la dimensión del trabajo remunerado: 
La ideología burguesa, de principios del siglo XX, (que) mandaba a las mujeres a casa, como "sirvientas". De esta forma, muchas mujeres que laboran en la agricultura, en talleres domésticos, en el comercio familiar, en la costura o la confección de alimentos, en el hogar, se insertaron en grupos demográficos que no ejercían trabajo remunerado o eran vistas como asistentes del jefe de hogar, no siendo trabajo contabilizado en los Censos de Población. ${ }^{9}$ (Baptista y Alves, 2019: 527)

Aplicándolo al cine, su presencia en el plató era, de hecho, casual o de auxilio para el marido. Al descubrir que las mujeres quedaron en custodia en la parte más técnica y menos artística de la profesión se cuestiona si esto tuvo alguna repercusión en la construcción "acrítica" tanto de la definición actual de la profesión como de su indicación en los títulos de las películas portuguesas.

Durante la investigación sobre la genealogía de la profesión de figurinista, en esta época específica, se encontraron similitudes entre España y Portugal, que en esos años recibieran dos dictaduras longevas: Portugal permanecerá bajo Salazar entre 1933 y 1974, mientras que España, oficialmente a partir de 1939, emergerá más lentamente del régimen de Franco, a través de un período llamado "Transición" sólo en 1975.

Son muchos los ejemplos materiales que nos hicieron pensar en una relación "propagandística" entre los dos países durante el franquismo y el salazarismo, sutilmente implementada visualmente también a través del vestuario cinematográfico. Fueron años en los que se le dio mucha importancia al cine en el campo de la propaganda (Piçarra, 2021) y muy a menudo, a través de un cuidadoso análisis de las coproducciones entre los dos países, resulta que por él pasaron muchos actores y actrices, tomando con ellos no solo productores y directores sino también técnicos especializados como, en el caso que nos interesa, los figurinistas.

Los estereotipos visuales (Street, 2001), fundamentalmente de género, difundidos tanto por la cinematografía ibérica como por los medios audiovisuales, No-Do (1943-1981) y Journal Português (1938-1951) sobre todo, ampliaron su radio de acción no sólo a través de una fuerte distribución cinematográfica entre España y Portugal pero también, y sobre todo, con el tránsito de trabajadores de un país a otro. Muchas coproducciones se rodaron en Portugal con actores y actrices españoles (por ejemplo, Joselito y Marisol) que, con su presencia, también fueron el vehículo de transmisión de conceptos, estereotipos y formas de vida para presentarse como "normalidad".

\footnotetext{
${ }^{9}$ A ideologia burguesa, do início do século XX, (que) remetia as mulheres para o lar, como "domésticas". Deste modo, muitas mulheres trabalhando na agricultura, em oficinas domésticas, no comércio familiar, na confeção de costura ou de alimentos, no domicílio, foram inseridas em grupos demográficos não exercendo trabalho remunerado ou vistas como auxiliares do chefe de família, não sendo o seu trabalho contabilizado nos Recenseamentos da Populaçã.
} 
Un ejemplo que sobresale sobre todos, se remonta a 1936, pocos años antes de la toma del poder de Franco, con la coproducción "Las tres gracias", la versión española de "Bocage" dirigida por José Leitão De Barros y protagonizada por actores y actrices españolas, entre ellos Alfredo Mayo. Incluso en España, fueron años en los que las mujeres no alcanzaron la visibilidad adecuada para poder desarrollar una carrera.

Manuel Comba (1902-1987), presente en todos los textos sobre arte cinematográfico español, no solo es el figurinista más importante de su tiempo, sino también Profesor Catedrático de la disciplina de Indumentaria en el Real Conservatorio. Le sigue Humberto Cornejo Arenillas (1895 - 1976), comenzando como diseñador independiente y seguirá siendo conocido en la historia del espectáculo como el fundador, en 1920, de la casa de modas Cornejo, aún en activo en la actualidad. A través del nombre del figurinista español Manuel Comba nos remontamos a otro dato importante de los inicios de la profesión.

Dado que los diseñadores de vestuario que enseñaron el arte y la técnica de la profesión también fueron hombres, el nombre del español Manuel Comba puede asociarse con el portugués de Manuel Francisco Dos Santos.

Durante muchas décadas, el 'costumier' Castelo-Branco, de su verdadero nombre Manuel Francisco dos Santos (1869-1934), que también enseña "indumentaria" en el Conservatorio, reina absolutamente en los escenarios de Lisboa. ${ }^{10}$ (V. Pavão Dos Santos, 1978: 83).

En territorio español, Manuel Comba poseía el doble papel de artista y de profesor: de hecho, no solo era el gran costumier del cine español entre los años ' 30 y ' 50 , sino también catedrático en el Conservatorio (Comba, 1944: 29).

La "Big history" destaca en sí misma un paradigma muy importante: la profesión de figurinista no está ligada a la destreza manual que había sido el hilo conductor entre las montadoras del cine mudo y las costureras y bordadoras. El paradigma nos muestra cómo la profesión de figurinista, durante estos primeros treinta años de dictadura, está atada al poder de la propaganda visual ${ }^{11}$. Las producciones y coproducciones que comienzan a circular entre España y Portugal refuerzan el vínculo político y fraternal no solo entre los dos países sino también y sobre todo entre las dos comunidades ibéricas que se reflejan entre sí. También es a través del tránsito de técnicos y artistas y su sabiduría que los estereotipos, censuras y estándares visuales pasan de un país a otro.

\footnotetext{
${ }^{10}$ Durante muitas decadas, reina absoluto sobre o que se veste nos palcos de Lisboa o 'costumier' CasteloBranco, de seu nome verdadeiro Manuel Francisco dos Santos (1869 - 1934), que além disso também ensina "indumentaria" no Conservatório.

${ }^{11}$ En el caso del fascismo italiano esta relación entre moda, cine y poder fue ampliamente estudiada por Sofia Gnoli en "L'eleganza fascista” (2017)
} 
Leitão de Barros dirigió la primera documentación y etnoficción del cine portugués, la primera película sonora, la primera película histórica y también las primeras coproducciones con España y Brasil. ${ }^{12}$ (Leitão de Barros \& Mantero, 2019: 114).

Volviendo a Portugal sería difícil destacar, desde este momento particular de la historia del cine, algunos nombres de mujeres trabajadoras que han colaborado más que dos veces como jefas de equipo. Según Monica Dall'Asta, durante muchas décadas, a partir del cine mudo, esta situación era muy frecuente.

Surge la pregunta de cómo lidiar con el número mucho mayor de mujeres cineastas que, a lo largo de toda su vida, solo fueron capaces de dirigir, escribir, producir, distribuir, etc., no más que un puñado de películas, o incluso una sola. Surgen varias preguntas más. Por ejemplo, ¿por qué tantas de ellas también eran actrices? ¿Podría esto indicar que el acceso de las mujeres a la dirección, producción y, a veces, incluso a la escritura de guiones, dependía de su entrada previa en la industria cinematográfica en un papel más tradicionalmente femenino, como el de actriz? (Dall'Asta, 2010: 43-44).

A menudo las mujeres solían entrar en el mundo del cine a través de sus maridos que ya trabajaban allí, o bien, siempre junto a sus maridos, daban vida a proyectos o productoras, realizando variadas tareas en una labor polifacética: secretarias, asistentes, etc. En Portugal, un caso es el de Helena Roque Gameiro, que se analizará a continuación ${ }^{13}$.

Paradójicamente, en las dos cinematografías, español y portugués, muy a menudo los personajes femeninos de la pantalla están relacionados con la profesión de "costurera" o en todo caso con profesiones relacionadas con el mundo textil: lavanderas, planchadoras, bordadoras, etc.

Centrándonos en Portugal, descubrimos las excepciones que se pueden encontrar entre los títulos de las pocas películas en las que no solo aparece el nombre de Anahory o el de Paiva: una sobre todo Helena Roque Gameiro, figurinista y artista de bordados. A diferencia de sus compañeros figurinistas, Roque Gameiro, en sus dos únicas apariciones cinematográficas, estuvo presente en el plató para acompañar el rodaje con sus asistentes y para asistir a la directora y actores ella misma.

\footnotetext{
12 Leitão de Barros dirigiu a primeira docuficção e etnoficção do cinema portugues, o primeiro filme sonoro, o primeiro filme histórico e também as primeiras co-produções com Espanha e Brasil.

${ }^{13} \mathrm{El}$ "Women film pioneers project" presenta ejemplos parecidos al largo de la historia del cine, concentrándose en el periodo mudo. Accesible en: https://wfpp.columbia.edu
} 
La colaboración en las 'Pupilas' requirió la presencia de Helena en el set, actividad que combinó con las clases en la Escola António Arroio. ${ }^{14}$ (Leitão de Barros y Mantero, 2019: 144).

Helena Roque Gameiro merece una biografía en el campo del cine y una presencia en la historia de la profesión que hasta ahora no se le ha concedido, ya que, con solo dos películas en su haber y una carrera artística muchas veces alejada del cine, no puede alcanzar la continuidad de las carreras establecidas de los diseñadores de vestuario portugueses mencionados al principio del párrafo.

Esposa de uno de los directores más activos de aquellos años, José Leitão de Barros, la encontramos como figurinista en As pupilas do Senhor Reitor en 1935 y en Bocage en 1936. Algunas fotos del rodaje documentan su presencia en el plató, mientras que las familias Roque Gameiro y Leitão de Barros confirman la presencia de materiales gráficos que la artista había realizado para ambas películas, que se perdieron en mudanzas y en un incendio de $1962^{15}$.

Si la experiencia como figurinista teatral de José Leitão de Barros está ampliamente documentada a través de los bocetos conservados en el repositorio digital del Museu Nacional do Teatro e da Dança ${ }^{16}$, el de su esposa Helena Roque Gameiro por tanto se pierde. Sin embargo, se puede recopilar alguna información para iniciar una genealogía que incluya también a las mujeres en la historia de la profesión de figurinista en Portugal.

En cuanto a la película de 1935 As pupilas do Senhor Reitor, leemos:

Los accesorios y el vestuario fueron diseñados y estilizados por Helena Roque Gameiro, y luego realizados por el sastre Paiva, en Oporto. ${ }^{17}$ (Leitão de Barros y Mantero, 2019: 142)

Por ejemplo, esta declaración contiene una historia completamente diferente a la que se transmite oralmente y que hace referencia a recuerdos personales y profesionales, según los cuales Álvaro Costa Paiva fue uno de los figurinistas más importantes, junto con otros colegas hombres: en realidad, entre las profesionales entrevistadas, queda una idea según la cual "Paiva" (como se le conocía en el ámbito teatral y cinematográfico) y su marca fue el resultado de una casa de moda que activa a principios

\footnotetext{
${ }^{14}$ A colaboração nas 'Pupilas' exigiu a presença de Helena no 'plateau', actividade que conjugou com as aulas na Escola António Arroio.

${ }^{15}$ Para más informaciones sobre la actividad cinematográfica de Helena Roque Gameiro leer Cucinotta (2020). Ademas el libro de Leitão de Barros y Mantero (2019) retrata partes importantes del espolio de documentos y cartas entre el director José Leitão de Barros y Helena Roque Gameiro.

16 http://www.matriznet.dgpc.pt/

17 Adereços e guarda-roupa foram desenhados e estilizados por Helena Roque Gameiro, e depois confecionados pela alfaiataria Paiva, no Porto".
} 
del siglo pasado, sobre todo en el teatro. Con el paso de los años, se ha convertido en un simple artesano que elaboraba el "guarda-roupa" por encargo.

El vestuario fue, una vez más, responsabilidad de Helena Roque Gameiro. Será desde Bocage, pero también gracias a las históricas procesiones que organizará, que José se connota con grandes presupuestos y producciones megalómanas. "Con Leitão de Barros todo fue genial, los vestidos de auténtica seda, el pelo fabuloso, todo lo mejor que existía", resume Carmen Dolores. (Leitão de Barros y Mantero, 2019: 148)

La artista plástica fue profesora de diseño en la Escuela de Artes Aplicadas, que dará lugar al actual Instituto Antonio Arroio. La colaboración estética y formal con el marido fue notable, hasta el punto de que José Leitão de Barros estuvo muy influenciado por las habilidades de Roque Gameiro y él mismo incluyó en el estudio de la escenografía una útil incursión en el vestuario.

Helena Roque Gameiro comenzó a exhibir acuarela a una edad temprana y se convertirá en la primera figurinista del cine portugués, al colaborar en las producciones de su esposo. (Leitão de Barros \& Mantero, 2019: 62).

Similar suerte corrió María Da Paz d'Orey, de la que aún no hay noticias seguras salvo que firmó dos películas, ambas de 1946: La mantilla de Beatriz dirigida por Eduardo García Maroto en coproducción con España y Camões de José Leitão de Barros. Ninguna carrera artística en el vestuario, solo dos determinadas colaboraciones: una historia bastante parecida a la de Gameiro, con quien casi seguro se cruzó gracias a la colaboración con Leitão de Barros.

¿Podemos poner a Helena Roque Gameiro y Maria da Paz D’Orey junto a Alberto Anahory? Si queremos apuntar a una "reescritura de la historia desde abajo", lo primero que hay que hacer es incluir mujeres que, a diferencia de los hombres, no tuvieron la oportunidad cultural, pero sobre todo material, para desarrollar grandes carreras artísticas en el campo cinematográfico. Incluso una simple colaboración será útil para mirar la historia del cine desde un punto de vista que incluye a las mujeres en contribuciones que transforman la prospectiva de género en los Film Studies, con una mirada desde otras profesiones.

\section{Años '60 y '70. Estado Novo y Cinema Novo: ¿Antiguo estereotipo?}

El segundo momento que queremos analizar comienza en 1963, año en el que Paulo Rocha, de regreso de Francia, decide rodar Os verdes anos, iniciando así lo que se 
llamará el "Cinema Novo" o "Novo Cinema". La peculiaridad de esta película está contenida en unas líneas de una entrevista del propio Rocha en la que declara:

Por lo general, estamos acostumbrados a sobrestimar la historia en relación con la mise-en-scène. En Os Verdes Anos, intentamos ir en contra de eso. Lo que más importaba era la relación entre la decoración y el personaje, el tratamiento del material cinematográfico. Fueron las líneas de fuerza, en un plano, las que le dieron su peso y su importancia. Es un cine artesanal, frente a un cine industrial, y una visión personal del autor, frente a un cine del productor. (Jornal de Letras e Artes, 6 de mayo de 1964, cit. Monteiro, 2000: 330).

Rafael Calado y Alda Cruz firman "decoración y vestuario": ambos no volverán a aparecer en ningún crédito de película. ¿Quiénes son? ¿Quién es Alda Cruz?

Nacida en 1936, Alda Cruz, más tarde conocida como Alda Rosa, es diseñadora gráfica y de muebles, socia fundadora en 1976 de la Associação portuguesa de Designers. En una breve biografía ${ }^{18}$ leemos que "se dedicó principalmente al diseño gráfico, pero también al diseño de mobiliario, escenografía y vestuario para ballet y cine" ${ }^{19}$.

La única película en la que vemos su nombre vinculado al vestuario es Os verdes anos. Esta película es, de hecho, un ejemplo que nos conduce a un aspecto muy particular de estos años: en casi todas las películas del Nuevo Cine, quienes firman el vestuario son figurinistas, muy a menudo mujeres, que no desarrollan una carrera artística, vienen de otras áreas, pasaron por casualidad o simplemente tienen alguna característica técnica, manual y organizativa, por lo que son enviadas al departamento de vestuario.

La misma modalidad se encuentra en Uma abelha na chuva, película de 1972 dirigida por Fernando Lopes, en la que Maria Helena Matos (1924 - 2015) firma "figurinos y adereços". Incluso Matos, a menudo confundida con la actriz del mismo nombre (19112002) fue en realidad una escultora y diseñadora de vidrio, que pasó al cine firmando una de las películas más refinadas y emblemáticas del "Nuevo $\mathrm{Cine}^{20}$, pero lo hizo de paso.

Para completar la información sobre estos veinte años, hemos decidido destacar la obra de Cristina Reis (n. 1945), quien desde el Teatro da Cornucopia, donde trabajó con Jorge Silva Melo y Luis Miguel Cintra, pasa a una gran colaboración con Paulo Rocha en el $A$ ilha dos amores, cuya preparación comenzó en 1969 para terminar 14 años después y solo se presentará al público portugués en 1991. En esta coproducción entre Portugal y

\footnotetext{
${ }^{18}$ Ligada al proyecto de investigaçión PTDC/EAT-HAT/121601/2010

${ }^{19}$ Dedicou-se sobretudo ao design gráfico, mas também ao design de mobiliário, cenografia e figurinos para bailado e cinema

${ }^{20}$ Novo Cinema
} 
Japón, Cristina Reis no solo firma el vestuario en una colaboración con Beatriz Alçada, sino también los decorados.

Beatriz Alçada, a su vez, también firmará el vestuario de Silvestre en 1981, dirigida por João Cesar Monteiro.

Se reconoce la importancia que sus espacios, vestuario, accesorios e imágenes jugaron en la traducción formal y visual de cada dramaturgia del director Luís Miguel Cintra, y el papel decisivo que jugaron en la construcción de la identidad de la compañía, llegando incluso a convertirse en una marca distintiva de la empresa Cornucopia. Además del teatro, Cristina Reis también idealiza escenarios y vestuario para cine y opera. (Barbara Coutinho, Maio 2020). ${ }^{21}$

Comúnmente, este trabajo en el cine solo se nombra, no se profundiza en él y aparece como un complemento a otra actividad más importante.

El cine del Antiguo Régimen valoraba el vestuario porque en realidad lo devolvía a una importancia que puede y debe estar ligada a su poder de persuasión y convicción directa sobre el espectador: les otorga grandes presupuestos (como afirma Carmen Dolores sobre el esplendor de las películas de José Leitão de Barros) y las deja prácticamente en manos de los hombres, excepto por las figurinistas que hemos nombrado. No solo directores y productores, sino también figurinistas masculinos que se han quedado solos en la historia que estamos tratando de construir y reescribir.

Con el Nuevo Cine, sin embargo, las premisas habían cambiado: lo que Paulo Rocha declaró en 1964 era en realidad un posicionamiento diferente de las producciones cinematográficas con respecto al espectador y viceversa: era una invitación a una lectura menos narrativa y más visual de la realidad, de los elementos materiales de la película. En la práctica, sin embargo, el valor simbólico que se le quiere dar al vestuario, como elemento material de la película, no corresponde a presupuestos más grandes sino sólo a la demanda de creatividad sin límites que sepa gestionar la brecha entre la idea del director, la de la figurinista y los pocos fondos disponibles para materializarlos.

Maria Helena Matos, Alda Cruz y Cristina Reis son ejemplos de mujeres que se encontraron exactamente en este limbo: realizaron trabajos artísticos y creativos, vinculados ahora al design, ahora a la escultura y al teatro. El cine, tocándolo de pasada una o dos veces, no resultó ser, o quizás más simplemente no podría ser, su principal fuente de sustento.

¿No será este el vínculo entre cine, moda y materialidad? La presencia de mujeres artistas que, antes de trabajar en el cine, trabajan directamente con el material artístico,

\footnotetext{
${ }^{21}$ https://www.mude.pt/artigos/cristina-reis-lisboa-1945_3.html
} 
desde un punto de vista manual y técnico que se convierte, una o dos veces, en dramaturgia cinematográfica tejida y entrelazada a través de los hilos de la narración.

Pero, el hecho más importante que concierne a los veinte años desde principios de los 60 hasta finales de los 70 fue otro. En esta época particular, Portugal pasa, a través de una Revolución, de una dictadura a la República.

Inmediatamente después de 1974, llega a Lisboa una figura que actuará como un punto de inflexión entre una primera y confusa generación de figurinistas y una segunda generación, que incluía figuras que aún practican la profesión en la actualidad.

Para la reconstrucción de una historia de la profesión de figurinista en Portugal, Jasmim de Matos (1942-1994) es una figura central del cine portugués. Nació en Angola y regresó a Portugal en 1974, inmediatamente después de la Revolução dos cravos, después de unos años en Londres por motivos políticos.

Es el único escenógrafo, o más exactamente, el único director de arte portugués que deja su marca, su sello personal en los filmes a los que da cuerpo, forma, volumen y color. (Benard, 2011: 963).

No solo es una figura ineludible en la historia del cine portugués, también es una figura inolvidable. El director de arte Jasmim fue, de hecho, el único profesional de este sector que tuvo derecho a un libro editado por la Cinemateca Portuguesa (1996) de homenaje por su temprana muerte, donde amigos y compañeros lo recuerdan con cariño.

El primer largometraje en el que trabajó fue Demonios de Alcácer-Quibir de José Fonseca e Costa, que se estrenará en 1977. Al empezar a trabajar en el cine trae toda una serie de innovaciones, reglas y hasta cierto orden a la profesión. Jasmim De Matos asume a menudo el papel de lo que hoy se llama "director de arte", es decir, firma juntos los decorados y el vestuario. Sin embargo, también es habitual que haya fichado solo a uno de los dos sectores. Desarrolla una carrera entre el cine y el teatro: esta fue su principal profesión hasta la fecha de su muerte. Por eso, es importante recordar su figura y su metodología de trabajo.

Precisamente por las reglas que trajo Jasmine a Portugal, los primeros equipos de vestuario finalmente comenzaron a perfilarse con un jefe de sector, asistentes y ayudantes. La historia oral comienza a juntar algunas piezas y, a través de las entrevistas, se descubrió que muchas figurinistas comenzaron a trabajar en el cine como asistentes de Jasmine. Una tercera generación de figurinistas que poblará, como veremos, la tercera fase histórica analizada por este artículo.

El concepto de analizar el cine desde nuevos puntos de vista distintos al del director nos lleva a relacionar a estos cuatro profesionales que podrían representar la segunda 
generación de diseñadores de vestuario, entre el fin del salazarismo y el nacimiento del Nuevo Cine.

Pese a ello, y teniendo como testimonio su propia historia "from below" que estamos intentando reconstruir, es innegable que el camino de las tres primeras figurinistas (Cruz, Matos y Reis) queda como una brecha solitaria en sus carreras. Esto también sucedió con Helena Roque Gameiro, artista plástica oficialmente "cedida" al cine por sólo dos producciones.

La entrada de Jasmim en escena nos hace reflexionar sobre las distintas posibilidades que se manejaban de manera diferente, según se tratara de un hombre o de una mujer. A pesar de la poca experiencia de Jasmim en la industria del vestuario (los colegas cuentan cómo su madre lo ayudaba a realizar o modificar las piezas), la profesión de figurinista fue lo que lo acompañó hasta su muerte, sin vacilaciones ni dudas. Por otro lado, no cabía duda de cuál era el nombre apropiado para su trabajo: escenarios y/o figurines, que de hecho era el más utilizado.

La generación de diseñadoras de vestuario (todas mujeres) que formó, cuenta que era una persona organizada, absolutamente creativa y con un gran sentido del gusto. Hay un análisis de João Pedro Bénard sobre Os demonios de Alcácer-Kibir que puede convertirse en un tema de reflexión sobre su metodología de trabajo.

Su primer trabajo de escenografía y vestuario en cine es para Os demónios de Alcacer-Kibir de José Fonseca e Costa (1975), un film de recursos financieros limitados, rodado en escenarios naturales y sobre todo en exteriores, donde consigue crear una unidad y una coherencia visual y da al filme un estilo proprio y en la época, provocadoramente innovador. Es la primera vez que en el cine portugués los objectos, los ornamentos, las vestimentas utilizadas tienen, más allá de la función plástica y utilitaria, una función narrativa, es decir, ayudan a caracterizar a los personajes y la estética, interactuando dialécticamente unos con los otros y no apareciendo aislados, de modo que crean la coherencia y unidad visual del filme. (João Pedro Benard, 2011: 963).

Maria Helena Matos, Alda Cruz, Cristina Reis y Jasmim de Matos son cuatro de los profesionales que asisten en la transición entre el cine de régimen y el Novo Cinema: los cuatro juntos representan la segunda generación de figurinistas del cine portugués. 


\section{Los años ' 80 y '90 y la profesionalización artística: ¿para quién?}

Como se mencionó en el párrafo anterior, Jasmim De Matos lleva consigo un valor fundamental para una correcta redacción de la genealogía de la profesión del figurinista: el valor de haber formado toda una generación de diseñadores de vestuario que, a finales de los '70, pero todos a partir de los '80 poblaron las películas del cine portugués.

Maria Gonzaga, Teresa Campos, Isabel Branco y Maria José Branco pueden ser consideradas como la "generación Jasmim" habiendo iniciado la profesión de figurinista y escenógrafa, directa o indirectamente, a partir de una colaboración, asistencia o prácticas con él. A partir de lo que, para simplificar, hemos denominado la "generación Jasmim", se formaron entonces otras figuras importantes como Rosario Moreira, Maria da Luz (Lucha) D'Orey, descendente de Maria Da Paz D’Orey, Silvia Grabowski, Carla Figueiredo, Patricia Doria, entre otras.

Si en los años 60 asistimos al nacimiento del Novo Cinema portugués, los 80 se caracterizan en cambio por una Nouvelle Vague de vestuario. Jasmim logra profesionalizar el departamento de vestuario en el cine portugués y de ahí nacen los nuevos jefes de equipo, que todas son mujeres.

Estas figurinistas, por primera vez en la historia de la profesión, desarrollarán carreras reales en el campo del cine y, solo en unos pocos casos esporádicos, pasarán del teatro al cine y viceversa. Es una generación que empieza a pasar por casualidad a los platós de cine: ellas mismos en las entrevistas de 2017 afirmaron que les atraía la curiosidad de visitar un plató y luego se quedaban allí para trabajar en él.

Teresa Campos acompañó a una actriz amiga en un plató y comenzó a echar una mano en el vestuario, Rosario Moreira fue contratada como niñera en un plató y allí se quedó como asistente de vestuario; María Gonzaga pasó por las más variadas funciones, desde el maquillaje a asistente de dirección, producción, hasta que logra instalarse en el departamento de vestuario.

A partir de las entrevistas, no solo se puede tejer un hilo conductor en la historia de la profesión, sobre todo se establecen unos patrones que se repetirán. Un ejemplo sobre todo es el reclamo de ser negociado con presupuestos muy limitados para la creación de trajes suntuosos o bien hechos. Otro caso fue la ausencia total de reglas sindicales para todo el sector durante muchos años 22 .

\footnotetext{
22 EI CENA-STE "Sindicato de todos os Trabalhadores de Espectáculos, do Audiovisual e dos Músicos" fue creado en 2017. Se empieza como una organización orgánica y salarial del sector de vestuarios con AGRA "Agrupamento guarda-roupa do audiovisual" creado en 2018.
} 
No por casualidad, todas estas mujeres con las que conversamos nos dijeron que para quedarse a trabajar en el cine se les ofreció ayudar en el vestuario: un concepto que no es nuevo si se presta atención a la evolución de la historia del cine.

Esta característica se pone en juego de forma espontánea y sigue relacionada no solo a los caminos y recurrencias de la historia, sino también y sobre todo a los estereotipos sociales y culturales vinculados al cine y su esfera masculina.

La peculiaridad de este proceso, como hemos enseñado, es que no comienza con el arte sino con la técnica. La mayoría de las figurinistas de los ' 80 y '90 probablemente, al empezar a trabajar en el cine, no han tenido una formación adecuada: estudios de moda, estudios de escenografía y cine, o incluso una preparación en el campo del teatro. Con frecuencia, las habilidades técnicas requeridas no eran académicas ni teóricas: se requerían fundamentos prácticos y algo de creatividad. A la pregunta: “¿Cuál fue tu formación? ¿Tuviste alguna formación?".

Teresa Campos contestó:

No tenía ninguna formación. Estuve ocho años como asistente. Trabajé con muchos figurinistas franceses y aprendí a hacer patines y raccords. ${ }^{23}$

Isabel Branco:

Mi experiencia es el design de muebles. Mientras tengas una formación en design, ya sea cortando ropa o haciendo muebles, empiezas a entender cómo se construyen las cosas. Ayuda de cualquier forma. ${ }^{24}$

Rosário Moreira:

Mi formación es en design gráfico en IADE. Se trata de papeles, colores, paginación. Me encuentro usando mucho la escala cromática cuando hago pinturas, patines, tintes, cuando selecciono ropa. Mi formación siempre está ahí. ${ }^{25}$

Esta transversalidad llevó a la mayoría a no preocuparse por la nomenclatura porque, absurdamente y al no haber recibido una formación adecuada, todas han declarado que no la veían como una preocupación y menos como un motivo de interés. Todas estas mujeres adquirieron experiencia en el plató, durante años de arduo trabajo, casi siempre en un ambiente exclusivamente masculino, en el que los departamentos

\footnotetext{
${ }^{23}$ Não tive formação nenhuma. Eu estive oito anos como assistente. Trabalhei com muitas figurinistas francesas e aprendi a fazer patines e raccords.

${ }^{24}$ A minha formação é design de moveis. Desde que tenhas uma formação em design, seja cortar roupa ou fabricar moveis, passas a perceber como é que as coisas se constroem. Ajuda de qualquer maneira.

${ }^{25}$ A minha formação é em design gráfico no IADE. Está tudo relacionado com papeis, cores, paginações. Dou por mim a utilizar muito a escala cromática quando faço tintas, patins, tingimentos, ao selecionar roupas. A minha formação está lá sempre.
} 
artísticos estaban poblados por hombres (guion, dirección, fotografía, escenografía,...) a los que les importaba poco la cuestión "superficial" del vestuario.

A la pregunta: “¿Crees que en Portugal hay alguna diferencia entre usar la palabra "guarda-roupa" y "figurino"?

Teresa Campos:

La palabra "guarda-roupa" tiene que ver con el poco valor que se le da al vestuario en las películas. En el pasado, la gente llamaba guardaropa como podían llamar armario. Como era un departamento de mujer y ropa, pasó a llamarse "guardaroupa" porque era donde se guardaba la ropa. Tenía que ver con la falta de práctica y la forma en que nos veían. Cuando empezamos en el cine, deberíamos haber luchado por la palabra "figurino" de inmediato. No nos valoramos mucho y nadie nos valoraba, seguimos con el "guarda-roupa". Hoy luchamos porque no hacemos guardaropa: yo hago figuras, un "figurino" de mis figuras. ${ }^{26}$

Isabel Branco:

"Aquí las terminologías son pésimas, no existen, como tampoco hay salario estipulado. Se preguntan unas con las otras para saber cómo es. ${ }^{27}$

Si el hecho de ser mujeres las ha perjudicado o no por un reconocimiento negado, la única forma de constatarlo es iniciar un análisis no solo de sus condiciones laborales sino también y sobre todo de su producción artística, entendiendo sus procesos creativos, observando sus materiales de preproducción y, finalmente, aprovechar las películas en las que colaboraron teniendo en cuenta la presencia del vestuario, buscando en su presencia no solo narrativas paralelas sino también "leitmotivs" para asociarlos a diversas y diferentes labores.

\section{Conclusiones}

El cambio de punto de vista respecto al proceso creativo es uno de los pilares fundamentales para comprender la importancia de otras profesiones artísticas en el

\footnotetext{
${ }^{26}$ A palavra guarda-roupa tem a ver com o pouco valor dado ao figurino nos filmes. Antigamente, as pessoas chamavam guarda-roupa como podiam chamar o roupeiro. Guarda-roupa é o armário. Como se tratava de um departamento de mulheres e roupa, passou a ser chamado guarda-roupa porque era onde se guardava a roupa. Tinha a ver com a falta de prática e a maneira como nos viam. Quando entramos para o cinema, devíamos ter logo lutado pela palavra figurino. Nos próprias não nos valorizávamos muito e ninguém nos valorizava, continuamos com "guarda-roupa". Hoje em dia lutamos porque não fazemos guarda-roupa: eu faço figuras, um figurino das minhas figuras.

${ }^{27}$ Aqui as terminologias são terríveis, não existem, assim como não existem os salários estipulados. Perguntam-se uns aos outros para saber como é
} 
cine. En el caso de la profesión de figurinista, el esfuerzo es doble, al no ser una profesión que exija expresamente un conocimiento directo de los materiales cinematográficos, muchas veces se omite.

Ahora bien, si no resulta productivo buscar razones que justifiquen el vacío de análisis que aún se percibe en esta materia, será más útil intentar cubrirlo. Una de las posibles causas de este desvío crítico puede resultar del análisis del cine solo a partir de los directores y, por otro lado, de su vestuario, sólo a partir de los objetos.

En el dossier temático de la Revista internacional de historia de la comunicación (v. 1, n. 10, 2018) Ana María Velasco Molpeceres se refiere a la moda y a los estudios sobre sus relaciones con los medios de comunicación definiéndolos "recientes", debido al "desinterés de la Academia por la prensa femenina que tuvo que esperar al desarrollo del movimiento feminista tras los sesenta para ser atendida (2018: 3).

En nuestro caso, el interés por una profesión artística que cuenta con la mayoría de mujeres, todavía no ha tenido su momento: la urgencia, que se trasmuta en tendencia, es profundizar primero a las mujeres directoras.

El cine portugués se presenta como un ejemplo de medio artístico de comunicación donde todavía no se ha encontrado el valor fílmico que ocupa el vestuario en la construcción dramática y visual de una película.

Todo el valor de la moda como medio de comunicación, revisitado y representado en el cine, se presenta, en los Fashion Studies, a través de su objeto (la ropa y al actor) sin su sujeto (el creador).

En realidad, no es suficiente hacer una lista de todas las personas que han construido la parte textil de las películas a lo largo de los años: lo que más importa es entender su relevancia en un marco general que contextualice el cine, finalmente, como un medio de comunicación creativo y artístico colectivo. Los mecanismos de ocultación del labor femenino que el cine ha producido hasta ahora, han mortificado las expresiones artísticas que, de cualquier forma, han resistido y se han adaptado.

Por otro lado, para una correcta inclusión del papel de la mujer en el cine, será importante entender qué profesiones han sido más accesibles, durante las diferentes épocas y los cambios sociales. Analizar solo a las directoras deja de fuera una pieza importante, no solo para incluir al vestuario y las figurinistas en un análisis más completo, sino también, y sobre todo, para llegar a la conciencia de que las mujeres que no han sido directoras, quizás tuvieron la voluntad de querer participar en la construcción visual de una película de otra manera, igualmente considerable.

Si la moda siempre fue considerada como de dominio femenino, el vestuario de cine es solo una reverberación de esta "guetización": una trasformación de lo que Luque Ortiz 
y Pérez Curiel (2018: 122) definen como "prensa femenina", escrita y gestionada por mujeres.

El hecho de que durante los años del Estado Novo la profesión de diseño de vestuario permaneciera en manos de hombres que supieron desarrollar carreras, como hemos visto, también en el campo didáctico y académico y no solo artístico, nos muestra cómo la importancia del vestuario en el cine es absolutamente proporcional al valor que el propio Estado les había otorgado, como fuente de difusión de estereotipos y arquetipos ya definidos por la propaganda.

Cabe señalar que las pocas mujeres a las que se ha descubierto con la investigación archivística no han tenido la posibilidad de una continuidad en su carrera. Hasta la fecha, esto también es uno de los problemas no resueltos de las mujeres directoras.

Y una vez más, la misma historia nos cuenta que en una profesión que había perdido el poder propagandístico de los años dictatoriales y no pudo recuperar a los fastos anteriores, salvo con apariciones fugaces esporádicas de profesionales "prestadas" al séptimo arte, un hombre, Jasmim De Matos, se encargó de poner orden en las cosas. A partir de este momento, parece que la profesión de figurinista en el cine portugués no ha logrado salir del estereotipo que la ve como "asistentes" de alguien más: el director, el escenógrafo, el productor. Se autodefinen como "jefes de Guarda-roupa" sin saber aceptar de buen grado el término "figurinista" en sus funciones.

No se ha logrado dejar atrás una definición atávica donde las mujeres siempre son consideradas, y ellas mismas se consideran, "ayudantes" de sus maridos ${ }^{28}$ (Baptista y Alves, 2019: 531). Un problema que siempre surge de una visión "masculinizada" de la realidad laboral.

El problema de la genealogía reconstruida hasta ahora existe cuando, hasta finales de los '90, en los títulos de las películas portuguesas, no es posible tener una idea clara de cómo se gestionaba la profesión. Surge la idea de que quizás simplemente no se ha manejado, pues ha sido relegado a un "women's thing" y descartado sin demasiada importancia como un simple "guarda-roupa".

Cuando Jacques Aumont aconseja analizar el cine teniendo en cuenta varios puntos de vista, no especificó diferencias de género en las otras profesiones del cine. Pese a ello, hasta hoy, después del director, las figuras que consiguen tener más visibilidad como coautores de la película son el director de fotografía y el músico, también estas profesiones prácticamente pobladas por hombres.

La forma negativa en que la moda sigue siendo considerada como el universo al que solo las mujeres pueden dedicarse, resulta en una devaluación, una ausencia de prácticas

28 "Auxiliares" dos maridos 
emancipadoras y una inexistencia de participación activa que tiene su inicio en la manera "unívoca" como siempre se ha considerado el cine a lo largo de su "Big History".

La moda ha sido considerada con frecuencia como una empresa "frívola", que al privilegiar la estética es acusada de vacuidad ideológica y vanidad por sus críticos. (...) La capacidad de la moda para generar discursos sobre todos los aspectos de la sociedad - género, sexualidad, clase, política, etc. - la convierte en una forma de arte fértil para la discusión. ${ }^{29}$ (Cousins, 2008: 7-8).

A través de su vínculo con la moda, en el vestuario cinematográfico a menudo se ha pasado por alto como un área viable de su análisis. La construcción sartorial (de sastrería) del cine a través de sus texturas textiles conduce a un estudio inverso del cine, según el cual el vestuario no es un elemento externo al análisis fílmico (Bruno, 2014). Más bien, se transforma en "costumes", que surgen de un conjunto de facetas diversas, las cuales transmiten al espectador un punto de vista definido.

\section{Referencias bibliográficas}

AUMONT, J., (2004), Les théories des cinéastes, Nathan

BAPTISTA, V. y MARQUES ALVES, P. (2019), As Mulheres trabalhadoras em Portugal (1890-1970): as representações sobre o trabalho remunerado e o trabalho não remunerado numa perspetiva feminista. XIV Jornadas nacionales de historia de las mujeres. Mar de Plata, Argentina

BENARD DA COSTA, J. (1996), Jasmim no cinema português, Ed. Cinemateca portuguesa

BENARD, J. P. (2011), Jasmim de Matos. Em Diccionario del cine Iberoamericano. España, Portugal Y America. Fundación SGAE y Fundacion Autor Edition.

BRUNO, G. (2014), Surface. Matters of Aesthetics, Materiality, and Media. University of Chicago Press.

BURKE, P., (2001), Eyewitnessing: The Uses of Images as Historical Evidence (2001), Cornell University Press.

CASTRO, I. (2000), Cineastas portuguesas 1874 - 1956. Camara municipal de Lisboa

\footnotetext{
${ }^{29}$ Fashion has frequently been cast as a 'frivolous' enterprise, which in privileging aesthetics becomes accused of ideological vacuouness and vanity by its critics. (...) Fashion's ability to generate discourses on all aspects of society - gender, sexuality, class, politics etc. - renders it a fértile art form for discussion.
} 
CASTRO, V. (2010), O papel da segunda pele, Athena

COMBA, M., (1944), El problema del vestuário em nuestras producciones históricas, in Cine experimental (1)

COOK, P. (1996), Fashioning the Nation. Costume and identity in British cinema, BFI publishing

CORDERO-HOYO y SOTO-VAZQUEZ (2020), Women in Iberian Filmic Culture. A Feminist approach to the Cinemas of Portugal and Spain, Intellect, Bristol, UK/Chicago, USA.

COUSINS, J. (2008), Unstitching the 1950s film á costumes: hidden designers, hidden meanings, University of Exeter

CUCINOTTA, C., (2018), Viagem ao cinema através do seu vestuario. Percursos de analise em filmes portugueses de etnoficção, Labcom

CUCINOTTA, C. (2020), Costume designers in Portugal: a trade between art and technique, relegated to the status of a 'woman's thing, en CORDERO-HOYO $y$ SOTO-VÁZQUEZ (coords.) Women in Iberian filmic culture. A feminist approach to the cinemas of Portugal and Spain (pp. 146 - 162), Intellect books.

DALL'ASTA, M (2008), Non solo dive. Pioniere del cinema italiano, Cineteca di Bologna

GNOLI, S. (2017), Eleganza fascista. La moda dagli anni Venti alla fine della guerra, Roma: Carocci editore.

LAURETIS, T. (1985), Aesthetic and feminist theory: rethinking women's cinema, New German Critique, No 3

LEITÃO DE BARROS J. y MANTERO A. (2019), Leitão de Barros. A biografia roubada, Editorial Bizâncio

LUQUE ORTIZ, S. y PÉREZ CURIEL, C. (2018), El empoderamiento femenino en las revistas de moda: ¿'Realidad o aspiración?, RIHC: Revista Internacional de Historia de la Comunicación, no 10, pp.122-149.

PAVÃO DOS SANTOS, V. (1978), A revista à portuguesa. Uma história breve do teatro de revista, Edições "O jornal”

MONTEIRO, P. F. (2000), Uma margem no centro: a arte e o poder do "novo cinema". En REIS TORGAL (coord.) O cinema sob o olhar de Salazar, Círculo de Leitores.

PENAFRIA, M. (2016), Propostas para a teoria do cinema. Teoria dos cineastas, Vol. 2

PEREIRA, A. C. (2016), A Mulher-Cineasta: Da arte pela arte a uma estética da diferenciação, LabCom. IFP. 
PIEROTTI, F. (2011), Colorare le figure. Il lavoro femminile sulla pellicola, in biancoenero, 570, maggio-agosto 2011, pag. 111-118

PIÇARRA, M. (2021), Projetar a Ordem. Cinema do Povo e Propaganda Salazarista 19351954. Os pássaros

RONDOLINO, G. (2000), Storia del cinema, Utet

SALLES, C., (2008), Crítica Genética - Fundamentos dos estudos genéticos sobre o processo de criação artística, EDUC

SALLES, C., (1998), Gesto inacabado. Processo de criação artística, FAPESP y Anablume

SCHOLZ, A. y ALVAREZ, M. (2018), Cineastas emergentes: mujeres em el siglo XXI, Iberoamericana Vervuert. Colección: aproximaciones a las culturas Hispánicas

SCHOLZ, A. (2020), The invisible women of Spanish cinema, en CORDERO-HOYO y SOTOVÁZQUEZ, (coords.) Women in Iberian filmic culture. A feminist approach to the cinemas of Portugal and Spain (p. 29 - 48), Intellect books

SIMMEL, (1998), La moda, Mondadori

STREET, S. (2001), Costume and cinema: dress code in popular film, Wallflower

THOMPSON, E. P. (1991), The Making of the English Working Class, Penguin Books

VELASCO MOLPECERES, A. M. (2018), Presentación dossier Comunicación y moda, en RIHC: Revista Internacional de Historia de la Comunicación, no 10, pp. 1-07. 